\title{
Experimental treatment of Staphylococcus aureus bovine intramammary infection using a guanine riboswitch ligand analog
}

\author{
C. Ster, ${ }^{*}$ M. Allard, ${ }^{*}$ S. Boulanger, ${ }^{*}$ M. Lamontagne Boulet, ${ }^{*}$ J. Mulhbacher, † D. A. Lafontaine, $†$ É. Marsault,† \\ P. Lacasse, $\S^{1}$ and F. Malouin ${ }^{* 1}$ \\ *Centre d'Étude et de Valorisation de la Diversité Microbienne (CEVDM), and \\ †Groupe ARN/RNA Group, Département de biologie, Faculté des sciences, Université de Sherbrooke, Sherbrooke, QC, Canada, J1K 2R1 \\ ‡Département de Pharmacologie, Institut de Pharmacologie de Sherbrooke, Faculté de médecine et des sciences de la santé, \\ Université de Sherbrooke, Sherbrooke, QC, Canada, J1H 5N4 \\ §Dairy and Swine Research and Development Centre, Agriculture and Agri-Food Canada, Sherbrooke, QC, Canada, J1M 0C8
}

\begin{abstract}
Staphylococcus aureus is a leading cause of intramammary infections (IMI). We recently demonstrated that Staph. aureus strains express the gene guaA during bovine IMI. This gene codes for a guanosine monophosphate synthetase and its expression is regulated by a guanine riboswitch. The guanine analog 2,5,6-triaminopyrimidine-4-one ( $\mathrm{PC} 1)$ is a ligand of the guanine riboswitch. Interactions between PC1 and its target result in inhibition of guanosine monophosphate synthesis and subsequent death of the bacterium. The present study describes the investigational use of PC1 for therapy of Staph. aureus IMI in lactating cows. The in vitro minimal inhibitory concentration of $\mathrm{PC} 1$ ranged from 0.5 to $4 \mu \mathrm{g} / \mathrm{mL}$ for a variety of Staph. aureus and Staphylococcus epidermidis strains and required a reducing agent for stability and full potency. A safety assessment study was performed, whereby the healthy quarters of 4 cows were infused with increasing doses of $\mathrm{PC} 1(0,150,250$, and $500 \mathrm{mg})$. Over the $44 \mathrm{~h}$ following infusions, no obvious adverse effect was observed. Ten Holstein multiparous cows in mid lactation were then experimentally infused into 3 of the quarters with approximately $50 \mathrm{cfu}$ of Staph. aureus strain SHY97-3906 and infection was allowed to progress for 2 wk before starting PC1 treatment. Bacterial counts reached then about $10^{3}$ to $10^{4} \mathrm{cfu} / \mathrm{mL}$ of milk. Infected quarters were treated with 1 of 3 doses of PC1 $(0,250$, or $500 \mathrm{mg})$ after each morning and evening milking for $7 \mathrm{~d}$ (i.e., 14 intramammary infusions of $\mathrm{PC} 1$ ). During the treatment period, milk from PC1-treated quarters showed a significant reduction in bacterial concentrations. However, this reduction of Staph. aureus count in milk was
\end{abstract}

Received June 29, 2012.

Accepted October 22, 2012

${ }^{1}$ Corresponding authors: Pierre.Lacasse@agr.gc.ca and Francois. Malouin@Usherbrooke.ca not maintained during the $4 \mathrm{wk}$ following the end of the treatment and only $15 \%$ of the PC1-treated quarters underwent bacteriological cure. The somatic cell count and the quarter milk production were not affected by treatments. Although bacterial clearance was not achieved following treatment with $\mathrm{PC} 1$, these results demonstrate that the Staph. aureus guanine riboswitch represents a relevant and promising drug target for a novel class of antibiotics for the animal food industry.

Key words: Staphylococcus aureus, mastitis, guanine riboswitch, therapy

\section{INTRODUCTION}

Bovine mastitis is an inflammation of the udder that results from infection or trauma, and represents a frequent and costly disease for dairy producers (Seegers et al., 2003). Intramammary infection is often caused by the contagious bacterium Staphylococcus aureus that is highly transmittable, especially during milking (Sears and McCarthy, 2003; Olde Riekerink et al., 2008). Staphylococcal IMI exemplify difficult-to-treat persistent infections and relapses can lead to a chronic mastitis disease. Antibiotic treatment of IMI is problematic partly because in vitro antibacterial susceptibility is a poor predictor of efficacy in chronically infected cows (Owens et al., 1997). Cure rates for Staph. aureus mastitis rarely achieve $50 \%$ with currently available therapies (Radostits and Done, 2007). Although reinfections that follow attempts to treat acute mastitis can be due to newly acquired strains, they are often the result of the persistence of the original infective organism (Barkema et al., 2006). Current therapy thus often fails to eradicate the infection. As a result, novel approaches to treat staphylococcal IMI are urgently needed (Oliver et al., 2011).

The mammalian host environment can modulate gene expression of bacteria, including that of Staph. aureus (Lowe et al., 1998; Allard et al., 2006). In vivo expression suggests the importance of a gene for bac- 
terial survival in the host and the analysis of Staph. aureus gene expression during infection should help to identify elements which may be useful as drug targets. As part of our efforts to discover new antibiotherapies, we recently reported that the Staph. aureus gene guaA is expressed during bovine mastitis and we documented its expression mechanism (Mulhbacher et al., 2010; Allard et al., 2012). In staphylococci, guaA is coding for a guanosine monophosphate (GMP) synthetase and this gene expression is under the control of a guanine riboswitch. In the absence of guanine, the structure of the guanine riboswitch folds into the "on" state, which allows transcription of the entire mRNA molecule and the subsequent expression of encoded proteins that include the GMP synthetase. In contrast, upon guanine binding to the aptamer domain (i.e., core of the riboswitch structure that accommodates the ligand), the riboswitch folds into the "off" state, forming a transcription terminator that prevents gene expression and GMP synthesis. Interestingly, we recently demonstrated that the guanine riboswitch can be targeted by a drug-like small-molecule ligand named 2,5,6-triaminopyrimidine4-one (PC1), which mimics guanine and can block gene expression and essential GMP synthesis (Mulhbacher et al., 2010). Noteworthy, both the function of guaA and its regulation seem essential for bacteria. Furthermore, we have previously demonstrated that in vitro, there is no development of resistance to PC1 in Staph. aureus after 30 passages in the presence of subminimal inhibitory concentrations of the drug, suggesting that mutations leading to a constitutive expression of gua $\mathrm{A}$ may not readily occur (Mulhbacher et al., 2010). It is, thus, possible that maintaining a functional riboswitch to control guaA expression is a vital process that bacteria cannot bypass, making guaA and its riboswitch potential new targets for chemotherapy. We also previously demonstrated that PC1 was able to significantly reduce Staph. aureus infection in a murine model of IMI (Mulhbacher et al., 2010). In this article, we evaluated the efficacy of PC1 for treatment of bovine mastitis to further validate the importance of the Staph. aureus guanine riboswitch as a novel drug target.

\section{MATERIALS AND METHODS}

All animal experiments were approved by the Agriculture and Agri-Food Canada local institutional animal care committee (Sherbrooke, QC, Canada) and conducted in accordance with the guidelines of the Canadian Council on Animal Care (Ottawa, ON, Canada).

\section{Bacterial Strains}

The Staph. aureus strain SHY97-3906, which was originally isolated from a clinical case of bovine mas- titis during lactation (Diarra et al., 2002), was used for experimental bovine IMI. Multilocus sequence typing was performed using the procedure previously described (Enright et al., 2000). Multilocus sequence typing analysis revealed that the sequence type of strain SHY97-3906 was ST151 (i.e., the same as the common bovine mastitis strain ET3 (RF122), a virulent clonal subtype known to cause important tissue damage and mortality in experimental mastitis in the mouse (Guinane et al., 2008). Strain SHY97-3906 was previously used in other projects related to the riboswitch inhibitor and to bacterial gene expression studies (Allard et al., 2006, 2012; Mulhbacher et al., 2010). Staphylococcus aureus Newbould (ATCC 29740), ATCC 29213 and Staphylococcus epidermidis ATCC1228 were used for antimicrobial agent susceptibility testing. Additional bovine mastitis strains were also included in antimicrobial agents susceptibility testing. Briefly, strains no. 3,557 , and 1290 were originally isolated from cows at the end of lactation with mastitis that persisted for at least $55 \mathrm{~d}$ between dry-off and calving. Strain no. $3 \mathrm{had}$ the ST352 that is the same found in multiple bovine isolates causing subclinical mastitis (Smyth et al., 2009; Hata et al., 2010).

\section{Susceptibility of Staph. aureus and Staph. epidermidis to Antimicrobial Agents}

The MIC of PC1 (Santa Cruz Biotechnology Inc., Santa Cruz, CA) and classical antibiotics were determined by a broth microdilution technique following the recommendations of the Clinical Laboratory Standard Institute (CLSI, 2011). Oxacillin, vancomycin, erythromycin, gentamicin, cephapirin, and enrofloxacin were all from Sigma-Aldrich (Oakville, ON, Canada) and pirlimycin hydrochloride was from Pfizer Animal Health (Kirkland, QC, Canada). The cation-adjusted Muller Hinton broth (CAMHB; Becton Dickinson Canada Inc., Mississauga, ON, Canada) used for susceptibility tests was supplemented with $1.5 \mathrm{~m} M$ dithiothreitol (DTT; Sigma-Aldrich) to protect PC1 from oxidative self-condensation (i.e., a dimerization associated with a change in color; Taylor et al., 1955) during compound preparation and in vitro tests.

\section{Initial Safety Assessment for PC1}

A preliminary safety assessment of $\mathrm{PC} 1$ was conducted to confirm the absence of a negative reaction to the doses to be used in the clinical trial. Four healthy cows in mid lactation and exempt of IMI in their 4 quarters were infused with 1 of 4 doses of PC1 $(0,150,250$, or $500 \mathrm{mg}$ in saline) in each quarter after the morning milking. Cows were monitored for $44 \mathrm{~h}$ at each of 4 
milkings for body temperature and udder redness and swelling. Individual quarter milk was also collected at each milking ( $\mathrm{n}=4$ for each PC1 dose) to measure milk production and to allow sample harvesting for determination of SCC ( $\mathrm{n}=4$ for each PC1 dose) and determination of the acute-phase protein milk amyloid A (MAA). For MAA, 1 additional sampling was done $6 \mathrm{~h}$ after the infusion of $\mathrm{PC} 1$ ( $\mathrm{n}=5$ for each $\mathrm{PC} 1$ dose). Milk amyloid A dosage was performed with the MAA assay kit from Tridelta Development Ltd. (Maynooth, Ireland) according to their recommendations. The SCC was determined in a commercial laboratory (Valacta Inc., Sainte-Anne-de-Bellevue, QC, Canada).

\section{Experimental IMI}

Before the animal trial, the relation between the absorbance of bacterial cultures (absorbance at a wavelength of $600 \mathrm{~nm}, \mathbf{A}_{600 \mathrm{~nm}}$ ) and colony-forming units was determined. The day of the challenge, a volume of the overnight culture of Staph. aureus in Mueller Hinton broth (MHB; Becton Dickinson Canada Inc.) was transferred to $200 \mathrm{~mL}$ of fresh MHB to obtain an $\mathrm{A}_{600 \mathrm{~nm}}$ of 0.1 and grown at $35^{\circ} \mathrm{C}$ until the $\mathrm{A}_{600 \mathrm{~nm}}$ reached a value corresponding to $10^{8} \mathrm{cfu} / \mathrm{mL}$ in the exponential phase of growth. For intramammary infusions, bacteria were then diluted in sterile physiological saline (Baxter Healthcare Corp., Deerfield, IL) to obtain approximately $50 \mathrm{cfu}$ in $3 \mathrm{~mL}$. The plating of the inoculum on TSA confirmed that it actually contained $59 \mathrm{cfu}$ in $3 \mathrm{~mL}$.

Ten healthy multiparous Holstein cows in mid lactation were housed at the Dairy and Swine Research and Development Centre of Agriculture and Agri-Food Canada (Sherbrooke, QC, Canada). Prior to experimental infection, SCC determinations and bacterial analysis of aseptic quarter milk samples were done to ensure that selected cows were free of IMI. After allowing cows to adapt to the barn (1 wk), experimental infusion of mammary quarters with bacteria was randomly performed in 3 of the 4 quarters of each cow after the evening milking according to a procedure previously described (Petitclerc et al., 2007) with few modifications. Briefly, before inoculation, teats were scrubbed with gauzes soaked in $70 \%$ ethanol. Teats were allowed to air dry and intramammary infusion of a bacterial suspension ( $3 \mathrm{~mL}$ containing $59 \mathrm{cfu}$ ) was performed into 3 of the 4 quarters. Immediately after infusion, all quarters were thoroughly massaged and teats were dipped in an iodophor-based teat sanitizer. Disposable gloves were worn throughout the procedure and disinfected before proceeding to the next animal. All quarters infused with Staph. aureus became infected and all cows showed clinical signs of mastitis the first few days after intramammary infusion of Staph. aureus (inflammation or poor milk appearance, or both). For animal welfare, when body temperature exceeded $40^{\circ} \mathrm{C}$ and persisted over a 24-h period, a nonsteroidal antiinflammatory drug was injected (Flunazine; Vétoquinol Canada Inc., Lavaltrie, QC, Canada; $1 \mathrm{~mL} / 45 \mathrm{~kg}$ of BW). During this study, 4 cows received 1 injection and 2 cows received 3 injections before the treatment period (infection period) and 1 cow received 1 injection and 1 cow received 3 injections during the treatment period. No impact was expected on any specific experimental treatment, as each cow received all of the treatments (see below).

\section{Milk Sample Collection}

Milk was collected using individual quarter milking units at morning milking and weighed for the determination of quarter milk production. Samples were taken 3 times per week except during the treatment period where samples were taken daily. Between milking of each cow, the milking units were thoroughly washed and disinfected with an iodine-based germicide detergent (K.O. Dyne; GEA Farm Technologies, Westmoreland, NY). All other materials in contact with milk were disinfected with $70 \%$ ethanol. After foremilk was discarded, a 10-mL aseptic milk sample was collected for each individual quarter in a 50-mL sterile vial. Milk samples were serially diluted and $100 \mu \mathrm{L}$ were plated on both tryptic soy agar (Becton Dickinson Canada Inc.) and mannitol salt agar plates (Becton Dickinson Canada Inc.) for Staph. aureus identification and colony-forming unit determinations. Plates were then incubated $24 \mathrm{~h}$ at $35^{\circ} \mathrm{C}$ before colony counting. The dilutions that showed between 30 and 300 colonies were considered for calculation of the bacterial concentration. Each dilution was plated in duplicate. A nonaseptic 50-mL sample was also taken from each quarter at milking for the determination of SCC (Valacta Inc.).

\section{Evaluation of PC1 Efficacy for Treatment of Experimental Staph. aureus IMI}

Experimental IMI were allowed to progress for 2 wk for bacterial counts to stabilize (usually reaching approximately $10^{3}$ to $10^{4} \mathrm{cfu} / \mathrm{mL}$ of milk) before treatment initiation. Intramammary treatments were initiated after morning milking and repeated twice per day after each milking for 7 consecutive days (a total of 14 intramammary infusions of PC1; i.e., starting after the morning milking at $\mathrm{d} 1$ and finishing at the evening milking at d 7). Within each cow, a quarter was randomly treated with saline $(50 \mathrm{~mL})$, whereas 2 others randomly received 1 of 2 doses of PC1 (250 
$\mathrm{mg}$ or $500 \mathrm{mg}$ in $50 \mathrm{~mL}$ ). The saline and $\mathrm{PC} 1$ doses were prepared with $1.5 \mathrm{mM}$ DTT to limit the oxidation self-condensation of PC1 before its infusion into the mammary glands. Aseptic and nonaseptic milk samples were taken every day at morning milking during the treatment period and once per week for 4 wk after the end of treatment (monitoring period) for the determination of viable bacterial concentrations and SCC as described above.

\section{Statistical Analysis}

Statistical analyses of the data were performed using the PROC MIXED of SAS (SAS Institute Inc., Cary, NC) as repeated measurements. The subject was treatment (cow) and cow was included as a fixed effect in the model. For the PC1 safety assessment, data contrasts were used to compare the 3 doses of $\mathrm{PC} 1$ with the saline treatment. For the experimental PC1 therapy, orthogonal contrasts were used to compare control quarters with those that received either dose of PC1 and to compare the 2 doses of PC1. The Tukey adjusted test was used for other treatment comparisons. The data from the pretreatment, treatment, and posttreatment (monitoring) periods were analyzed separately. Pretreatment data (colony-forming units, milk production, and SCC) were used as covariables for the analysis of data of the treatment and monitoring periods. For the analysis of SCC and bacterial counts, data were $\log _{10}$ transformed before analysis.

\section{RESULTS}

\section{Antimicrobial Agent Activity}

The MIC of PC1 ranged from 0.5 to $4 \mu \mathrm{g} / \mathrm{mL}$ for a variety of Staph. aureus and Staph. epidermidis (Table 1 ). As the oxidative self-condensation of PC1 (Taylor et al., 1955) could impair its in vitro activity, the in vitro activity of PC1 was evaluated in the presence of a reducing agent (DTT). The lowest concentration of DTT that provided PC1 its maximal antibacterial activity was $1.5 \mathrm{mM}$, whereas the MIC of DTT itself was $>75 \mathrm{mM}$. Using a freshly made $\mathrm{PC} 1$ solution, the MIC of PC1 against Staph. aureus ATCC 29213 was established at $2 \mu \mathrm{g} / \mathrm{mL}$ and 64 to $128 \mu \mathrm{g} / \mathrm{mL}$ with or without DTT, respectively. For all the strains tested, the MIC of PC1 was greatly improved by the presence of DTT, whereas DTT had no effect on the MIC of the other antimicrobial agents tested (data not shown).

\section{Safety Assessment Study}

In a preliminary safety assessment study, 3 doses of PC1 and saline $(0,150,250$, and $500 \mathrm{mg})$ were directly infused in the 4 quarters of 4 healthy cows immediately after morning milking as done with other commercially available drugs for the treatment of bovine mastitis. The SCC, quarter milk production, and concentration of the acute-phase protein MAA were not affected by treatments during the $44 \mathrm{~h}$ following infusion of $\mathrm{PC} 1$ (Table 2). Intramammary infusion of PC1 also did not affect the body temperature, which was maintained around $38^{\circ} \mathrm{C}$ for each cow. Neither redness nor swelling was observed at the milkings for any of the quarters. Because no obvious side effect was observed with the infusion of PC1 into the mammary glands of mice (Mulhbacher et al., 2010) or dairy cows during this safety assessment assay, we judged PC1 to be safe to be used for the rest of the study.

\section{Evaluation of PC1 for the Treatment of IMI}

2,5,6-Triaminopyrimidine-4-one was then used for the treatment of 10 experimentally infected cows. The 30 infected quarters (3 per cow) were infused after ev-

Table 1. The MIC of 2,5,6-triaminopyrimidine-4-one (PC1) and classical antibiotics against 2 staphylococcal species

\begin{tabular}{|c|c|c|c|c|c|c|c|c|c|}
\hline Strain & \multicolumn{9}{|c|}{$\operatorname{MIC}^{1}(\mu \mathrm{g} / \mathrm{mL})$} \\
\hline \multicolumn{10}{|l|}{ Staphylococcus aureus } \\
\hline ATCC 29213 & $64-128$ & 2 & $0.12-0.25$ & 1 & 0.5 & $0.25-0.5$ & 0.25 & 0.25 & $0.12-0.25$ \\
\hline Newbould & 128 & $1-2$ & 0.12 & 1 & 0.25 & 0.25 & 0.12 & 0.25 & $0.06-0.12$ \\
\hline 557 & $64-128$ & $1-2$ & 0.12 & $1-2$ & 0.25 & $0.25-0.5$ & $0.06-0.12$ & 0.25 & 0.06 \\
\hline 1290 & $64-128$ & 1 & $0.12-0.25$ & 2 & $0.25-0.5$ & 0.25 & 0.12 & 0.25 & 0.12 \\
\hline \multicolumn{10}{|l|}{ Staphylococcus epidermidis } \\
\hline ATCC 12228 & 64 & $2-4$ & $0.06-0.12$ & 2 & $0.12-0.25$ & 0.06 & 0.12 & $0.06-0.12$ & 0.12 \\
\hline
\end{tabular}

${ }^{1}$ Antibiotic MIC were determined in cation-adjusted Muller Hinton broth (CAMHB; Becton Dickinson Canada Inc., Mississauga, ON, Canada). The MIC of oxacillin (OXA), vancomycin (VAN), erythromycin (ERY), gentamicin (GEN), cephapirin (CEP), pirlimycin (PIR), and enrofloxacin (ENR) were not modified in the absence or presence of $1.5 \mathrm{~m} M$ dithiothreitol (DTT; data not shown).

${ }^{2}$ The MIC of PC1 was reduced by the presence of $1.5 \mathrm{mM}$ DTT. The MIC of DTT is $>75 \mathrm{mM}$. 
Table 2. Effect of 1 intramammary infusion of saline or 2,5,6-triaminopyrimidine-4-one (PC1) at the indicated dose to healthy cows on SCC, acute-phase protein milk amyloid A (MAA), and quarter milk production over a 44 -h period

\begin{tabular}{lccc}
\hline & $\begin{array}{c}\mathrm{SCC} \\
\text { Infusion }^{1}\end{array}$ & $\begin{array}{c}\text { Quarter milk } \\
\text { production } \\
(\mathrm{kg} ; \mathrm{n}=5)^{2,3}\end{array}$ & $\begin{array}{c}\text { MAA } \\
\left(\log _{10} / \mathrm{mL} \text { of milk; } \mathrm{n}=4\right)^{2,3}\end{array}$ \\
\hline Saline & $4.94 \pm 0.12$ & $3.09 \pm 0.40$ & $225.75 \pm 25.75$ \\
PC1 & $5.29 \pm 0.10$ & $2.24 \pm 0.21$ & $290.43 \pm 34.90$ \\
$100 \mathrm{mg}$ & $5.21 \pm 0.13$ & $2.57 \pm 0.15$ & $263.23 \pm 35.92$ \\
$250 \mathrm{mg}$ & $5.18 \pm 0.10$ & $3.34 \pm 0.37$ & $255.65 \pm 39.87$ \\
$500 \mathrm{mg}$ & & & \\
\hline
\end{tabular}

${ }^{1}$ Saline and the different doses of PC1 were randomly infused in the 4 quarters of 4 healthy dairy cows.

${ }^{2}$ Data presented are LSM \pm SEM. No statistical difference was observed for these parameters.

${ }^{3}$ After infusion of $\mathrm{PC} 1$ or saline, cows were monitored during $44 \mathrm{~h}$ at each of 4 milkings. Individual quarter milk was collected at each milking $(\mathrm{n}=4$ for each PC1 dose) to measure milk production and to allow sample collection for determination of SCC ( $\mathrm{n}=4$ for each PC1 dose) and determination of MAA. For MAA, 1 additional sampling was done $6 \mathrm{~h}$ after the infusion of $\mathrm{PC} 1$ ( $\mathrm{n}=5$ for each $\mathrm{PC} 1$ dose).

ery milking during $7 \mathrm{~d}$ with either 250 or $500 \mathrm{mg}$ of PC1 or saline (all prepared in $1.5 \mathrm{~m} M$ DTT). During the treatment period, the number of viable bacteria was significantly lower in the quarters that received PC1 compared with those that received saline (Figure $1 ; P=0.02)$. No difference was observed between the 2 doses of $\mathrm{PC} 1$, which similarly affected the bacterial count $(P=0.48)$. After the treatment period (monitoring period), the bacterial count in PC1-treated quarters increased and was no longer statistically different from that of control quarters (Figure 1A). The cure rate, defined as no detectable bacteria (cfu) for 2 milk samples taken 2 wk apart, with the first sample taken 1 wk after the end of the treatment, was $15 \%$ for the PC1-treated quarters versus $0 \%$ for the quarters that received saline $(P=0.2)$. No significant difference was observed in quarter milk production or SCC over the treatment and monitoring periods (Table 3 ).

\section{DISCUSSION}

The Staph. aureus strain SHY97-3906 was used in this study to evaluate the efficacy of PC1 for the treatment of bovine IMI. We chose this strain because it originated from a typical clinical mastitis case and for its sequence type (ST151), which is representative of many mastitis isolates. Also, we showed that this strain was as susceptible as others to PC1 in vitro and that gene guaA (under the control of the guanine riboswitch target of PC1) was strongly expressed during bovine mastitis similarly to that found for 3 other mastitis isolates (Allard et al., 2012).

All staphylococci strains tested were affected by the antibiotic activity of $\mathrm{PC} 1$, showing MIC ranging from 0.5 to $4 \mu \mathrm{g} / \mathrm{mL}$ (Table 1 ). In our previous report (Mulhbacher et al., 2010), because of the high level of efficacy of PC1 in a mouse mastitis model of infection, we soon realized that the oxidative self-condensation of PC1 (Taylor et al., 1955) might have impaired its in vitro activity. Inversely, it seemed that the microaerobic environment (i.e., low oxidative environment) of the mastitic milk (Mayer et al., 1988) might have improved its activity in the mouse (Mulhbacher et al., 2010). Indeed, the addition of $1.5 \mathrm{mM}$ DTT to the PC1 preparation greatly improved its in vitro MIC by protecting PC1 against oxidation (Table 1). In the presence of $1.5 \mathrm{~m} M$ DTT, the MIC of PC1 gets closer to the MIC of antibiotics (cephapirin, pirlimycin, and enrofloxacin) commonly used for the treatment of bovine mastitis. Interestingly, $\mathrm{PC} 1$ is also effective against Staph. epidermidis (MIC of 2 to $4 \mu \mathrm{g} / \mathrm{mL}$ ), which is one of the CNS frequently causing IMI. Indeed, although Staph. aureus is one of the most prevalent bacterial species recovered from mastitis cases occurring during lactation in Canadian farms, the CNS are also often involved in bovine mastitis and have drawn more and more attention in recent years (Thorberg et al., 2009; Reyher et al., 2011). In addition, we have previously shown the in vitro activity of $\mathrm{PC} 1$ against a methicillinresistant Staph. aureus strain isolated from a human (Mulhbacher et al., 2010), despite its multi-resistance to traditional drugs ( $\beta$-lactams, ciprofloxacin, erythromycin, gentamicin, and tetracycline). A new treatment mechanism such as that represented by PC1 is, therefore, most certainly of interest considering the recent emergence of bovine methicillin-resistant Staph. aureus, which have been shown to be transmittable to humans (García-Álvarez et al., 2011; Haran et al., 2012).

Our preliminary safety assessment for the use of PC1 in cows yielded no obvious adverse effect. In addition, PC1 is well tolerated in rodents (Scientific Committee on Consumer Products of the European Commission, 2008). In short, the NOAEL (no observed adverse effect level, in repeated doses administered in rats by ga- 
A

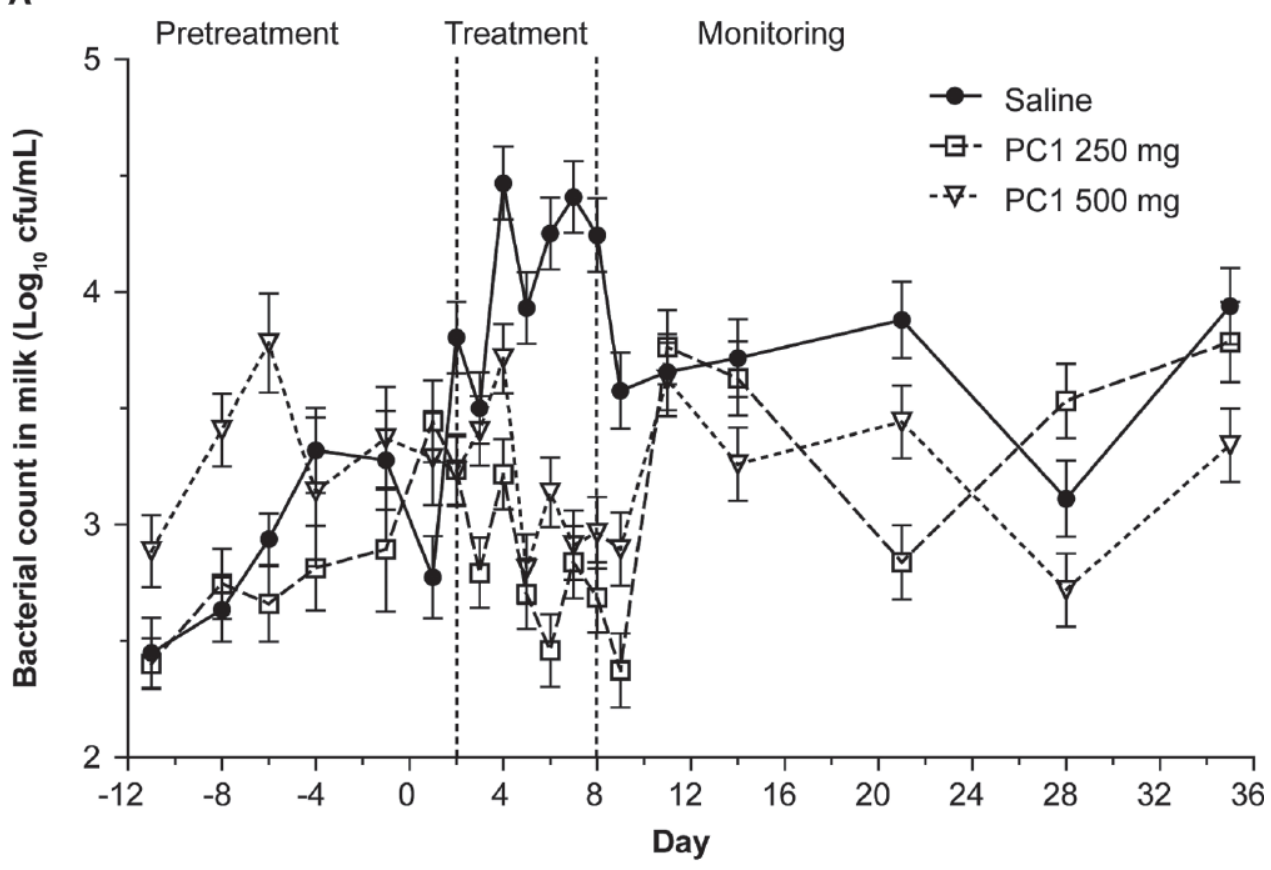

B

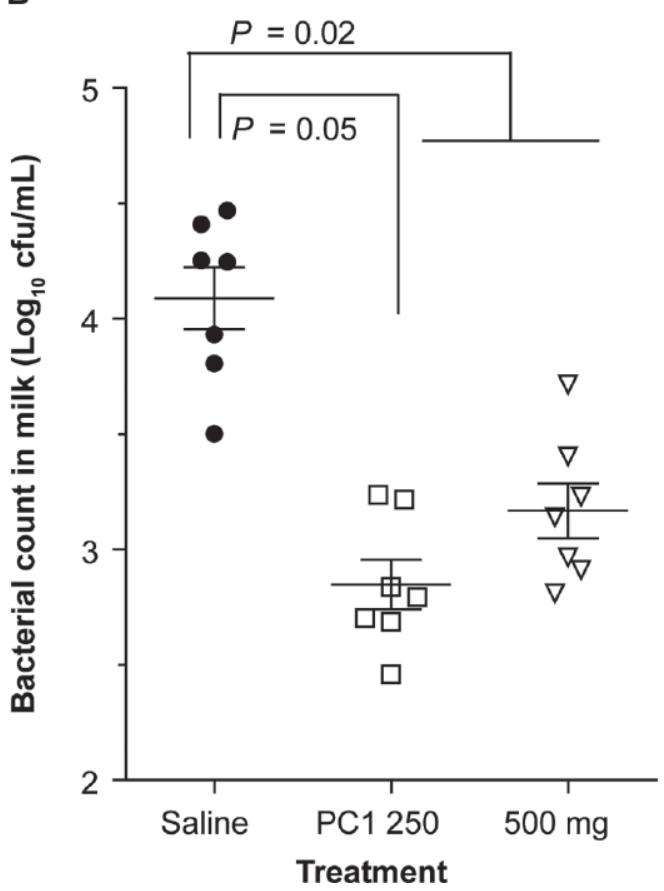

Figure 1. Experimental treatment of Staphylococcus aureus bovine IMI with 2,5,6-triaminopyrimidine-4-one (PC1). Ten Holstein multiparous cows in mid lactation were experimentally infused in 3 quarters with 59 cfu of Staph. aureus strain SHY97-3906 and infection was allowed to progress for $2 \mathrm{wk}$ before starting PC1 treatment at d 1 (pretreatment period). Each of the 10 cows was then treated with PC1 (250 or $500 \mathrm{mg}$ ) or saline for $7 \mathrm{~d}$ in 3 infected mammary quarters, respectively. Each of those treatments was infused twice daily (a total of 14 intramammary infusions of PC1) starting after the morning milking at $\mathrm{d} 1$ and finishing at the evening milking at $\mathrm{d} 7$ (treatment period). (A) Kinetics of the bacterial concentrations in milk $\left(\log _{10} \mathrm{cfu} / \mathrm{mL}\right)$ for each group during the pretreatment, treatment, and monitoring periods. Each dot represents the LSM \pm SEM of the bacterial concentrations in milk obtained for 10 quarters (10 cows). (B) Distribution of the bacterial concentrations in milk during the entire treatment period shown in A. Each dot represents the average bacterial count (cfu/mL) for each day of the 7-d treatment period for each group. Horizontal bars represent the LSM of bacterial counts over the treatment period for the different groups and vertical bars are the SEM. Orthogonal contrasts indicated that PC1 significantly reduced the bacterial count (cfu/mL) milk but that no difference existed between the 2 doses of PC1 during the treatment period. 
Table 3. Effect of the intramammary infusion of saline or 2,5,6-triaminopyrimidine-4-one (PC1) for $7 \mathrm{~d}$ on SCC and quarter milk production for quarters experimentally infected with Staphylococcus aureus over the treatment and monitoring periods

\begin{tabular}{lccccc}
\hline & \multicolumn{2}{c}{$\mathrm{SCC}^{1}\left(\log _{10} / \mathrm{mL}\right.$ of milk $)$} & & \multicolumn{2}{c}{ Quarter milk production $^{1}(\mathrm{~kg})$} \\
\cline { 2 - 3 } \cline { 5 - 6 } Infusion & Treatment & Monitoring $^{2}$ & & Treatment & Monitoring $^{2}$ \\
\hline Saline & $6.20 \pm 0.10$ & $6.29 \pm 0.11$ & & $3.69 \pm 0.07$ & $3.52 \pm 0.12$ \\
PC1 & & & & $3.72 \pm 0.07$ & $3.51 \pm 0.12$ \\
$250 \mathrm{mg}$ & $6.03 \pm 0.10$ & $6.20 \pm 0.11$ & & $3.66 \pm 0.07$ & $3.60 \pm 0.12$ \\
$500 \mathrm{mg}$ & $6.17 \pm 0.11$ & $6.01 \pm 0.12$ & &
\end{tabular}

${ }^{1}$ Data presented are LSM \pm SEM. No statistical difference was observed for these parameters.

${ }^{2}$ Parameters were monitored for the 4 wk that followed the end of treatments.

vage) was determined to be $200 \mathrm{mg} / \mathrm{kg}$ of $\mathrm{BW}$ per day (once daily, $28 \mathrm{~d}, 7 \mathrm{~d}$ per week). Of note, $\mathrm{PC} 1$ is also a nonribosylable analog that differentiates its molecular structure from canonical purines (such as guanine) or pyrimidines, thus preventing incorporation into nucleic acids and off-target effects (Mulhbacher et al., 2010). These data further support the potential success of the new drug class and will provide guidelines for future compounds of the PC1 (pyrimidine) scaffolds.

The present study is the first report on the use of PC1 for experimental therapy of bovine IMI. Although only $15 \%$ of the PC1-treated quarters were cured (vs. $0 \%$ for the untreated controls, $P=0.2$ ), intramammary infusions of PC1 significantly reduced the viable counts of Staph. aureus during bovine IMI (Figure 1). The PC1 dose of $250 \mathrm{mg}$ reduced the milk bacterial load of 1.23 $\log _{10}$, on average, during the treatment period (Figure 1B). Interestingly, the 500-mg dose of PC1 was not more efficient than the $250-\mathrm{mg}$ dose and correlated with the observation that the $500-\mathrm{mg}$ dose displayed more oxidative self-condensation of PC1 (i.e., a dimerization associated with a change in color) during preparation of the high-dose solution in the laboratory, despite the presence of $1.5 \mathrm{mM}$ DTT. Although stability, dosage, and formulation of the drug will need to be improved in future studies, our results demonstrate that the interruption of Staph. aureus guaA expression by PC1 can translate in a significant antibacterial activity in cows. 2,5,6-Triaminopyrimidine-4-one is the first member of this new class of antibiotics. Before pursuing the development of this new drug class, it was necessary to show a proof of concept in cows. At this time, it is difficult to know if an approximately $1 \log _{10}$ decrease in bacterial count would represent a useful outcome in the field but it supports the idea that new molecules can be designed to improve the efficacy of PC1. Also, our experimental model represents quite a challenge [i.e., an infusion of bacteria through the teat sphincter and directly up into the cistern, thus also bypassing the keratin layer (natural defense) of the teat canal]. The fact that all infused mammary quarters of all 10 cows rapidly developed clinical mastitis upon bacterial infusion corroborates the robustness of the challenge and it is possible that naturally infected cows would better respond to treatment. Now that the proof of concept is done, future experiments should include new analogs of PC1 and a known commercial antibiotic as a control to put in context the relative difficulty in achieving bacteriological cures in this experimental model. Future experiments should also demonstrate in vivo efficacy against a variety of Staph. aureus strains.

The US Food and Drug Administration issued draft guidance intended to help reduce the development of resistance to medically important antimicrobial drugs used in food-producing animals (US FDA, 2010). Hence, an increasing demand exists to come up with new antibiotic products that can specifically be used in the animal food industry. The development of a novel drug class that tackles specific pathogens such as Staph. aureus in the agri-food sector would be most welcome. Indeed, $\mathrm{PC} 1$ is one of the rare new classes of antibacterial molecules (novel scaffold and mode of action) discovered since 1968. In fact, only the oxazolidinones (approved in 2000) fit in this category (Powers, 2004). Preliminary riboswitch binding results confirmed that structural variations of ligands are indeed accommodated by the guanine riboswitch, indicative of available space in the riboswitch, and that both purine and pyrimidine scaffolds are tolerated in the binding site (Gilbert et al., 2006; Mulhbacher et al., 2010). This opens the way for finding analogs of PC1 that still bind to the Staph. aureus guanine riboswitch and that may be less subject to oxidative self-condensation.

\section{CONCLUSIONS}

Our data showed that PC1 can target Staph. aureus and Staph. epidermidis. Although stability, dosage, and formulation will need to be improved, PC1 can be safely administrated to dairy cows and can reduce Staph. aureus concentrations in experimentally infected quarters. The staphylococcal riboswitch is a valid drug 
target and a continued exploration of therapeutic applications for PC1 and derivatives for the treatment of bovine mastitis have to be carried on.

\section{ACKNOWLEDGMENTS}

This research was financed by the Natural Science and Engineering Research Council of Canada (NSERC, Ottawa, ON, Canada); Alberta Milk (Edmonton, AB, Canada); Dairy Farmers of New Brunswick (Sussex, NB, Canada), Nova Scotia (Lower Truro), Ontario (Mississauga), and Prince Edward Island (Charlottetown); Novalait Inc. (Québec, QC, Canada); Dairy Farmers of Canada (Ottawa); Canadian Dairy Network (Guelph, ON, Canada); Agriculture and Agri-Food Canada (Sherbrooke, QC, Canada); Public Health Agency of Canada (PHAC, Ottawa); Technology PEI Inc. (Charlottetown); Université de Montréal (Montréal, QC, Canada); and University of Prince Edward Island (Charlottetown) through the Canadian Bovine Mastitis Research Network (Sainte-Anne-de-Bellevue, QC, Canada). We also acknowledge funding support from CIHR and NSERC (discovery grant 89758-2010) to D. A. Lafontaine and F. Malouin, respectively. D. A. Lafontaine is a CIHR New Investigator scholar. Studentship support was also provided to M. Allard by the Faculté des sciences of Université de Sherbrooke. We also thank Caroline Roy, Philippe Bernier Dodier, and Lisette St-James for their technical assistance, as well as the barn staff of the Dairy and Swine Research and Development Centre of Agriculture and Agri-Food Canada for the good care of the cows.

\section{REFERENCES}

Allard, M., H. Moisan, E. Brouillette, A. L. Gervais, M. Jacques, P. Lacasse, M. S. Diarra, and F. Malouin. 2006. Transcriptional modulation of some Staphylococcus aureus iron-regulated genes during growth in vitro and in a tissue cage model in vivo. Microbes Infect. 8:1679-1690.

Allard, M., C. Ster, C. L. Jacob, D. Scholl, M. S. Diarra, P. Lacasse, and F. Malouin. 2012. The expression of a putative exotoxin and an $\mathrm{ABC}$ transporter during bovine intramammary infection contributes to the virulence of Staphylococcus aureus. Vet. Microbiol. http://dx.doi.org/10.1016/j.vetmic.2012.09.029. In press.

Barkema, H. W., Y. H. Schukken, and R. N. Zadoks. 2006. Invited review: The role of cow, pathogen, and treatment regimen in the therapeutic success of bovine Staphylococcus aureus mastitis. J. Dairy Sci. 89:1877-1895.

CLSI (Clinical and Laboratory Standards Institute). 2011. Performance standards for antimicrobial susceptibility testing: Twentyfirst Informational Supplement M100-S21. Vol. 31. CLSI, Wayne, PA.

Diarra, M. S., D. Petitclerc, and P. Lacasse. 2002. Response of Staphylococcus aureus isolates from bovine mastitis to exogenous iron sources. J. Dairy Sci. 85:2141-2148.

Enright, M. C., N. P. Day, C. E. Davies, S. J. Peacock, and B. G. Spratt. 2000. Multilocus sequence typing for characterization of methicillin-resistant and methicillin-susceptible clones of Staphylococcus aureus. J. Clin. Microbiol. 38:1008-1015.
García-Álvarez, L., M. T. G. Holden, H. Lindsay, C. R. Webb, D. F. J. Brown, M. D. Curran, E. Walpole, K. Brooks, D. J. Pickard, C. Teale, J. Parkhill, S. D. Bentley, G. F. Edwards, E. K. Girvan, A. M. Kearns, B. Pichon, R. L. R. Hill, A. R. Larsen, R. L. Skov, S. J. Peacock, D. J. Maskell, and M. A. Holmes. 2011. Methicillinresistant Staphylococcus aureus with a novel mecA homologue in human and bovine populations in the UK and Denmark: A descriptive study. Lancet Infect. Dis. 11:595-603.

Gilbert, S. D., S. J. Mediatore, and R. T. Batey. 2006. Modified pyrimidines specifically bind the purine riboswitch. J. Am. Chem. Soc. 128:14214-14215.

Guinane, C. M., D. E. Sturdevant, L. Herron-Olson, M. Otto, D. S. Smyth, A. E. Villaruz, V. Kapur, P. J. Hartigan, C. J. Smyth, and J. R. Fitzgerald. 2008. Pathogenomic analysis of the common bovine Staphylococcus aureus clone (ET3): Emergence of a virulent subtype with potential risk to public health. J. Infect. Dis. 197:205-213.

Haran, K. P., S. M. Godden, D. Boxrud, S. Jawahir, J. B. Bender, and S. Sreevatsan. 2012. Prevalence and characterization of Staphylococcus aureus, including methicillin-resistant Staphylococcus aureus, isolated from bulk tank milk from Minnesota dairy farms. J. Clin. Microbiol. 50:688-695.

Hata, E., K. Katsuda, H. Kobayashi, I. Uchida, K. Tanaka, and M. Eguchi. 2010. Genetic variation among Staphylococcus aureus strains from bovine milk and their relevance to methicillin-resistant isolates from humans. J. Clin. Microbiol. 48:2130-2139.

Lowe, A. M., D. T. Beattie, and R. L. Deresiewicz. 1998. Identification of novel staphylococcal virulence genes by in vivo expression technology. Mol. Microbiol. 27:967-976.

Mayer, S. J., A. E. Waterman, P. M. Keen, N. Craven, and F. J. Bourne. 1988. Oxygen concentration in milk of healthy and mastitic cows and implications of low oxygen tension for the killing of Staphylococcus aureus by bovine neutrophils. J. Dairy Res. 55:513-519.

Mulhbacher, J., E. Brouillette, M. Allard, L. C. Fortier, F. Malouin, and D. A. Lafontaine. 2010. Novel riboswitch ligand analogs as selective inhibitors of guanine-related metabolic pathways. PLoS Pathog. 6:e1000865.

Olde Riekerink, R. G. M., H. W. Barkema, D. F. Kelton, and D. T. Scholl. 2008. Incidence rate of clinical mastitis on Canadian dairy farms. J. Dairy Sci. 91:1366-1377.

Oliver, S. P., S. E. Murinda, and B. M. Jayarao. 2011. Impact of antibiotic use in adult dairy cows on antimicrobial resistance of veterinary and human pathogens: A comprehensive review. Foodborne Pathog. Dis. 8:337-355.

Owens, W. E., C. H. Ray, J. L. Watts, and R. J. Yancey. 1997. Comparison of success of antibiotic therapy during lactation and results of antimicrobial susceptibility tests for bovine mastitis. J. Dairy Sci. 80:313-317.

Petitclerc, D., K. Lauzon, A. Cochu, C. Ster, M. S. Diarra, and P. Lacasse. 2007. Efficacy of a lactoferrin-penicillin combination to treat $\beta$-lactam-resistant Staphylococcus aureus mastitis. J. Dairy Sci. 90:2778-2787.

Powers, J. H. 2004. Antimicrobial drug development-The past, the present, and the future. Clin. Microbiol. Infect. 10(Suppl. 4):2331.

Radostits, O. M., and S. H. Done. 2007. Veterinary medicine: A Textbook of the Diseases of Cattle, Sheep, Pigs, Goats and Horses. 10th ed. Elsevier Saunders, New York, NY.

Reyher, K. K., S. Dufour, H. W. Barkema, L. Des Côteaux, T. J. DeVries, I. R. Dohoo, G. P. Keefe, J. P. Roy, and D. T. Scholl. 2011. The National Cohort of Dairy Farms - A data collection platform for mastitis research in Canada. J. Dairy Sci. 94:1616-1626.

Scientific Committee on Consumer Products of the European Commission. 2008. Opinion on 2,5,6-triamino-4-pyrimidinol sulfate. European Cosmetic, Toiletry and Perfumery Association (COLIPA) no. A143, SCCP/1122/07. 17th plenary, Sep. 30, 2008. Scientific Committee on Consumer Products, Brussels, Belgium.

Sears, P. M., and K. K. McCarthy. 2003. Management and treatment of staphylococcal mastitis. Vet. Clin. North Am. Food Anim. Pract. 19:171-185. (vii.). 
Seegers, H., C. Fourichon, and F. Beaudeau. 2003. Production effects related to mastitis and mastitis economics in dairy cattle herds. Vet. Res. 34:475-491.

Smyth, D. S., E. J. Feil, W. J. Meaney, P. J. Hartigan, T. Tollersrud, J. R. Fitzgerald, M. C. Enright, and C. J. Smyth. 2009. Molecular genetic typing reveals further insights into the diversity of animalassociated Staphylococcus aureus. J. Med. Microbiol. 58:13431353.

Taylor, E. C. Jr., H. M. Loux, E. A. Falco, and G. H. Hitchings. 1955. Pyrimidopteridines by oxidative self-condensation of aminopyrimidines. J. Am. Chem. Soc. 77:2243-2248.
Thorberg, B.-M., M.-L. Danielsson-Tham, U. Emanuelson, and K. Persson Waller. 2009. Bovine subclinical mastitis caused by different types of coagulase-negative staphylococci. J. Dairy Sci. 92:4962-4970.

US FDA (Food and Drug Administration). 2010. FDA news release: FDA issues draft guidance on the judicious use of medically important antimicrobials in food-producing animals. June 28, 2010. FDA, Silver Spring, MD. 